Cite this: RSC Adv., 2014, 4, 19737

\title{
The role of solubility and critical temperatures for the efficiency of sorbitol clarifiers in polypropylene
}

\author{
Zsuzsanna Horváth, ${ }^{\star a b}$ Benjámin Gyarmati, ${ }^{c}$ Alfréd Menyhárd, ${ }^{\text {ab }}$ Petar Doshev, ${ }^{d}$ \\ Markus Gahleitner, dózsef Varga ${ }^{\text {ab }}$ and Béla Pukánszky ${ }^{\text {ab }}$
}

The optical properties of polypropylene (PP) were modified by nine different sorbitol type clarifiers available commercially or synthesized in the study. The solubility of the clarifiers in PP was estimated by thermodynamic model calculations. The results showed that the solubility of these additives in PP is small, a few 1000 ppm at most. Solubility is determined by the chemical structure of the sorbitol, and the heat of fusion of the latter changes solubility by at least one order of magnitude. Solubility can be estimated reasonably by the Flory-Huggins lattice theory. The morphology of most sorbitols transforms at a temperature much below their melting point upon heating. This transformation, which is accompanied by crystal perfection, seems to influence melting and solubility. A fibrillar structure forms upon the cooling of molten sorbitols, but the diameter of the fibrils is much larger than those forming in the polymer melt. The nucleating effect of the clarifier depends on solubility, but also on processing conditions. Nucleus density is related to the amount of dissolved clarifier. A close correlation was found between the Flory-Huggins interaction parameter of sorbitols and the smallest achievable haze, which can be explained by the effect of solubility and nucleus density.

Received 5th March 2014 Accepted 11th April 2014

DOI: 10.1039/c4ra01917b

www.rsc.org/advances already quite some time ago to determine correlations among polymer type, nucleating agent content, processing conditions and the optical properties of polymer products. ${ }^{3,4}$ The results showed that both polymer properties, including melt flow rate (MFR) and chain structure, and processing conditions strongly influence transparency and other optical characteristics.

Recently the use of polypropylene for the production of transparent products became industrial practice due to the low haze achieved by the proper design of polymer structure and the appropriate selection of additives, but also due to the acceptable price of this polymer. ${ }^{1,5,6}$ Low haze materials are usually prepared from random copolymers and the desired optical properties are achieved by the use of clarifiers, which are mostly different sorbitol derivatives, ${ }^{7-13}$ even if 1,3,5-benzenetrisamides have appeared as an alternative in recent years. ${ }^{\mathbf{1 4 , 1 5}}$ It is an accepted fact now that these additives dissolve in the polymer and generate a microcrystalline structure during cooling thus improving haze. ${ }^{16,17}$ Quite a few papers deal with the structure of the clarifier after its crystallization, the mechanism of nucleation and clarification, and the optical properties of PP. ${ }^{16-20}$

Smith et al. ${ }^{16}$ for example, carried out a fundamental and very thorough study on the binary system of polypropylene and 1,3:2,4-bis(3,4-dimethylbenzylidene) sorbitol (DMDBS). They determined the solubility of the additive by optical microscopy (OM) and differential scanning calorimetry (DSC) and created a non-equilibrium phase diagram describing brilliantly the various phases forming upon cooling or heating and their structure in the entire composition and in a wide temperature
${ }^{a}$ Laboratory of Plastics and Rubber Technology, Department of Physical Chemistry and H-1521 Budapest, Hungary. E-mail: zshorvath@mail.bme.hu

${ }^{b}$ Institute of Materials Science and Environmental Chemistry, Research Center for Natural Sciences, Hungarian Academy of Sciences, P.O. Box 286, H-1519 Budapest, Hungary

${ }^{c}$ Soft Matters Group, Department of Physical Chemistry and Materials Science, Budapest University of Technology and Economics, Budafoki út 8, H-1111 Budapest, Hungary

${ }^{d}$ Borealis Polyolefine GmbH, St.-Peter-Strasse 25, A-4021 Linz, Austria 
range. Later they used the same principles and approach for the study of the solubility of a new clarifier 1,2,3-tridesoxy-4,6:5,7bis-O-[(4-propylphenyl) methylene]-nonitol (TBPMN) ${ }^{17}$ in PP. However, these excellent works raised at least as many questions as they solved. Sorbitols are polar compounds which cannot dissolve in PP in large quantities. Dissolution is further hindered by the fact that the melting temperature of DMDBS is very high, $273.7^{\circ} \mathrm{C}$. Processing temperatures never reached this temperature in the study cited above, ${ }^{\mathbf{1 6}}$ thus the solubility limits determined for the two clarifiers, i.e. 2.5 and $5.0 \mathrm{wt} \%$, respectively, are rather surprising. In practice an order of magnitude smaller amount is used efficiently and haze usually deteriorates already above a few thousand ppm. The contradiction might be explained by the fact that the detection level of optical microscopy is in the range of $0.1 \mu \mathrm{m}$ and DSC signals are also size dependent, ${ }^{21-23}$ while the crystalline fibrils formed from sorbitols are claimed to be of nanometer size..$^{\mathbf{2 4 , 2 5}}$ The papers do not explain the role of the network formed by the clarifier during nucleation and the authors did not study the effect of clarifier structure on solubility and efficiency. Finally, the transformation of the clarifier at considerably lower temperatures than their melting point has not been mentioned in these two, or in fact in any other papers published.

Considering the published information and the questions mentioned above, the goal of our study was to investigate the solubility of a number of commercial and specially synthesized sorbitol clarifiers in PP, check at least magnitudes by model calculations and compare the predicted values to measured ones. We show that sorbitol crystals may transform upon heating, discuss the possible effect of this transformation on solubility and efficiency, and relate these latter to the chemical structure of the sorbitol.

\section{Experimental}

The polypropylene used in the study was the non-stabilized base powder of the RE 420 MO grade produced and supplied by Borealis Polyolefine GmbH. The melt flow rate (MFR, ISO 1133) of the polymer at $230{ }^{\circ} \mathrm{C}$ and $2.16 \mathrm{~kg}$ is $12 \mathrm{~g} / 10 \mathrm{~min}$ and its ethylene content is $3.5 \mathrm{wt} \%$. The polymer is a reactor grade which is based on a $4^{\text {th }}$ generation Ziegler-Natta catalyst and it has a weight average molecular weight, $M_{\mathrm{w}}$, of $195 \mathrm{~kg} \mathrm{~mol}^{-1}$ and a polydispersity, $M_{\mathrm{w}} / M_{\mathrm{n}}$, of 5 . Four sorbitol type commercial clarifiers were obtained from Milliken, USA, and another five were synthesized in our laboratory. The chemical name, source and abbreviation of the clarifiers used are compiled in Table 1 and their structure is presented in Fig. 1.

The synthesis of DBS is described here as an example. This product corresponds to the commercial grade Millad 3905. 91.1 $\mathrm{g}(0.5 \mathrm{~mol})$ sorbitol was dissolved in $200 \mathrm{ml}$ water and $118.9 \mathrm{~g}$ $(0.625 \mathrm{~mol}) p$-toluenesulfonic acid hydrate was added to the solution. After the dissolution of the solid components $91.5 \mathrm{ml}$ (0.9 mol) benzaldehyde was introduced during vigorous stirring. Moderate heat generated in the reaction mixture and precipitation of the crystalline material began. After $75 \mathrm{~min}$, additional $100 \mathrm{ml}$ of water was added to the viscous mixture to make stirring possible, followed by further $100 \mathrm{ml}$ after 3 and 4.25 hours, respectively. After 5.5 hours reaction time the mixture was neutralized with the aqueous solution of $30 \mathrm{~g}$ $\mathrm{NaOH}$ until a slightly basic solution was obtained. The nice, white, crystalline material was filtered and then a suspension was prepared in water and filtered again. $104.7 \mathrm{~g}$ product was obtained after drying. The product was dispersed in $750 \mathrm{ml}$ water containing $7 \mathrm{~g}$ hydroxyl amine hydrochloride and $5.3 \mathrm{~g}$ sodium carbonate and stirred at $80{ }^{\circ} \mathrm{C}$ in order to remove unreacted benzaldehyde. Stirring was continued until the strong odor of the solution disappeared. The next day the material was filtered, washed with distilled water and dried. The product was characterized by NMR, FTIR and DSC. The following chemical shifts were obtained for DBS $(400 \mathrm{MHz}$, DMSO-d6, $\delta)$ : 3.279-4.130 (m, 8H, saccharide $\mathrm{CH}$ and $\left.\mathrm{CH}_{2}\right)$; 4.364 (t, 1H, $\left.\mathrm{CH}_{2} \mathrm{OH}\right) ; 4.813$ (d, 1H, $\left.\mathrm{CHOH}\right) ; 5.600$ (s, 2H, $\left.\mathrm{ArCH}\right)$; $7.354(\mathrm{~m}, 10 \mathrm{H}, \mathrm{ArH})$. Yield was about $50 \%$, purity $90 \%$, and melting point $216.3{ }^{\circ} \mathrm{C}$. The procedure was practically the same for D4ClBS and D4NBS, and only the solvent was different for D3MoBS and D4MoBS $(25 \mathrm{ml}$ methanol and $200 \mathrm{ml}$ cyclohexane was used instead of water).

The stabilizers (1000 ppm Irganox 1010 and 1000 ppm Irganox 168) and the clarifiers were homogenized with the polymer in a Brabender W $50 \mathrm{EH}$ internal mixer at $210{ }^{\circ} \mathrm{C}$ for 10 min. The melt was transferred to a Fontijne SRA 100 compression molding machine to produce plates of $1 \mathrm{~mm}$ thickness. Compression molding was done at $190{ }^{\circ} \mathrm{C}$ for $5 \mathrm{~min}$. Samples and specimens cut from the plates were used for further study. The melting and crystallization characteristics of the samples were determined by differential scanning calorimetry (DSC) using a Perkin Elmer DSC 7 equipment. 3-5 mg samples were heated to $220{ }^{\circ} \mathrm{C}$ at $10{ }^{\circ} \mathrm{C} \min ^{-1}$ heating rate, kept there for 5

Table 1 Chemical name, source and abbreviation of the sorbitols used in the study

\begin{tabular}{|c|c|c|c|c|c|}
\hline Abbreviation & Chemical name & Source & $\mathrm{R}_{1}$ & $\mathrm{R}_{2}$ & $\mathrm{M}\left(\mathrm{g} \mathrm{mol} \mathrm{mol}^{-1}\right)$ \\
\hline D4NBS & 1,3:2,4-bis( $p$-nitrobenzylidene)sorbitol & Laboratory & $\mathrm{NO}_{2}$ & $\mathrm{H}$ & 448 \\
\hline D4MoBS & 1,3:2,4-bis $(p$-methoxybenzylidene)sorbitol & Laboratory & $\mathrm{OCH}_{3}$ & $\mathrm{H}$ & 418 \\
\hline D3MoBS & 1,3:2,4-bis ( $m$-methoxybenzylidene)sorbitol & Laboratory & $\mathrm{H}$ & $\mathrm{OCH}_{3}$ & 418 \\
\hline D4ClBS & 1,3:2,4-bis( $p$-chlorobenzylidene)sorbitol & Laboratory & $\mathrm{Cl}$ & $\mathrm{H}$ & 428 \\
\hline DBS & 1,3:2,4-dibenzylidenesorbitol & Laboratory & $\mathrm{H}$ & $\mathrm{H}$ & 358 \\
\hline DBS & 1,3:2,4-dibenzylidenesorbitol & Millad 3905 & $\mathrm{H}$ & $\mathrm{H}$ & 358 \\
\hline MDBS & 1,3:2,4-bis( $p$-methylbenzylidene)sorbitol & Millad 3940 & $\mathrm{CH}_{3}$ & $\mathrm{H}$ & 386 \\
\hline DMDBS & 1,3:2,4-bis(3,4-dimethylbenzylidene)sorbitol & Millad 3988 & $\mathrm{CH}_{3}$ & $\mathrm{CH}_{3}$ & 414 \\
\hline DOPMN & 1,2,3-tridesoxy-4,6:5,7-bis-O-[(4-propylphenyl)methylene]nonitol & Millad NX 8000 & & & 484 \\
\hline
\end{tabular}




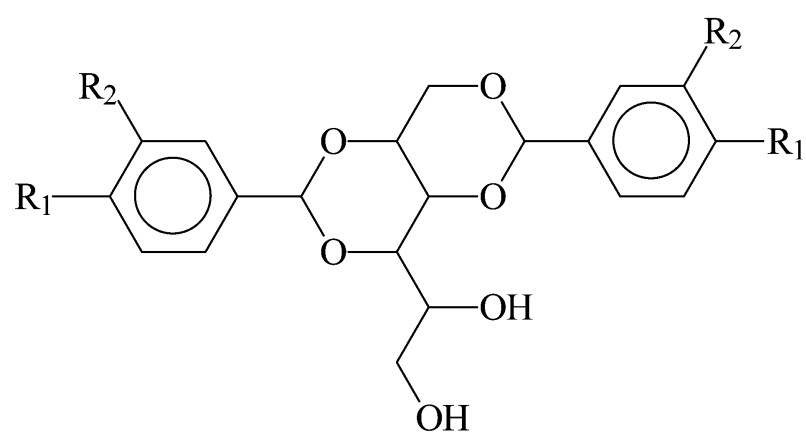

dibenzylidene sorbitols

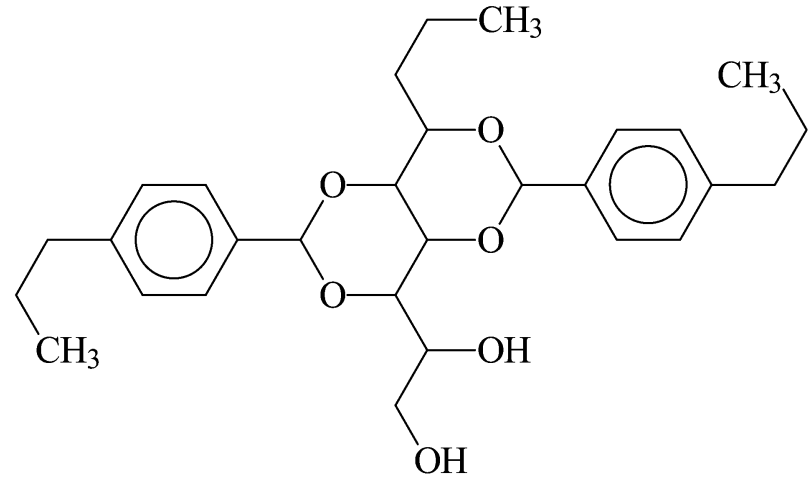

DOPMN, Millad NX 8000

Fig. 1 Chemical structure of the sorbitol clarifiers used in the study.

min to erase thermal history and then cooled down to $50{ }^{\circ} \mathrm{C}$ with the same rate to record crystallization characteristics. After $1 \mathrm{~min}$ holding time the samples were heated again to $200^{\circ} \mathrm{C}$ at $10{ }^{\circ} \mathrm{C} \min ^{-1}$ rate to determine melting temperature and the heat of fusion. The optical behavior of the polymers was characterized by haze measurements carried out on the $1 \mathrm{~mm}$ thick compression molded plates according to the ASTM D-1003-95 standard using a Hunterlab ColorQuest XE equipment. Crystallization and crystal transformation were studied by polarization optical microscopy (OM) using a Zeiss Axioscop equipped with a Leica DMC 320 digital camera and a Mettler FP82 type hot stage. The micrographs were recorded with the Leica IM50 software. The crystal structure of the original and the transformed sorbitols was studied by XRD using a Phillips PW 1830/ PW 1050 equipment with $\mathrm{CuK} \alpha$ radiation at $40 \mathrm{kV}$ and $35 \mathrm{~mA}$ anode excitation between 3 and $35^{\circ} 2 \theta$ angles.

\section{Results and discussion}

First solubility limits and the effect of sorbitol crystallinity on it are checked by model calculations and then we show the transformation of the crystalline structure of the sorbitol upon heating and determine characteristic temperatures. The effect of solubility, transformation, and the chemical structure of the additive on clarification and nucleation efficiency is discussed in the final section of the paper.

\subsection{Solubility}

As mentioned above, the limited solubility of sorbitol clarifiers is an accepted fact and their high efficiency is explained by the dissolution of the compound in PP at the high temperature of processing and its crystallization prior that of the polymer during cooling. ${ }^{20}$ The solubility limit at the temperature of the solidification of PP determines the threshold concentration of nucleation. The phenomenon is demonstrated well by Fig. 2 showing the dependence of the peak temperature of crystallization on the concentration of the clarifier. Below certain, relatively small clarifier concentration crystallization temperature remains constant that is explained by the existence of a eutectic temperature at low clarifier contents. ${ }^{16}$ Efficient

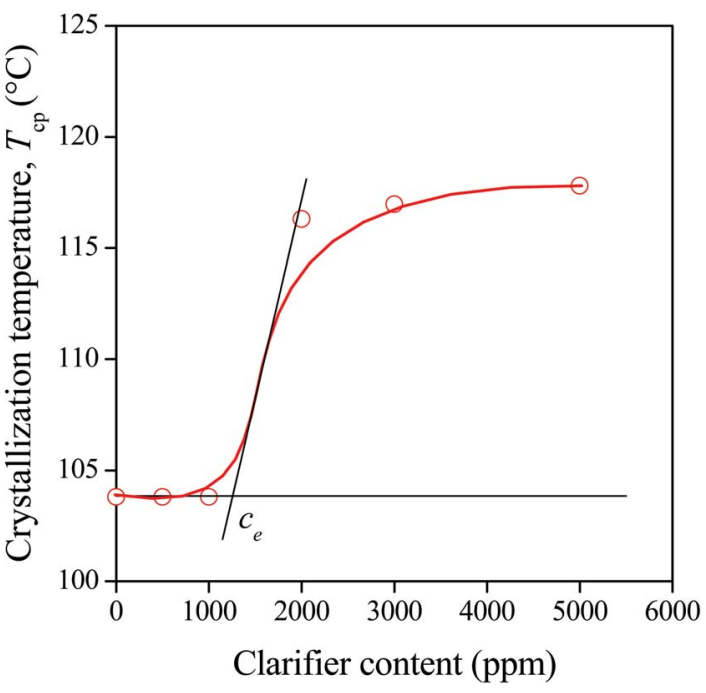

Fig. 2 Effect of clarifier content on the peak temperature of crystallization of PP containing the DMDBS (Millad 3988) clarifier. Determination of the threshold concentration of nucleation.

nucleation begins above this concentration and a plateau value is reached at a few thousand ppm additive concentration. The correlation presented in Fig. 2 allows us the determination of an experimental solubility value $\left(c_{\mathrm{e}}\right)$ at the temperature of solidification.

One would expect very small solubility of the rather polar sorbitol molecules in PP, because their interaction with each other must be much stronger than with the polymer which is capable to interact only by weak dispersive forces. Földes ${ }^{26,27}$ showed experimentally that only about $0.1 \mathrm{wt} \%$ of phenolic antioxidants of similar polarity and molecular weight as our clarifiers dissolve in PE, which explains the low threshold level indicated by Fig. 2. Solubility is hindered further by the crystallinity of the additive; the heat of fusion must be compensated by interactions or by melting, the former being rather weak as described above.

The dissolution of an additive in a polymer is determined by the free energy of mixing $\left(\Delta G_{\mathrm{m}}\right)$ : 


$$
\Delta G_{\mathrm{m}}=\Delta H_{\mathrm{m}}-T \Delta S_{\mathrm{m}}
$$

which must be negative for spontaneous dissolution. $\Delta H_{\mathrm{m}}$ is the enthalpy and $\Delta S_{\mathrm{m}}$ the entropy change of mixing in eqn (1). The thermodynamic condition of equilibrium is defined as the equality of chemical potential in the two phases:

$$
\Delta \mu_{\mathrm{s} 1}=\Delta \mu_{\mathrm{s} 2}
$$

where $\Delta \mu_{\mathrm{s} 1}$ and $\Delta \mu_{\mathrm{s} 2}$ are the changes of chemical potential during the dissolution of the sorbitol, corresponding to the polymer-lean and polymer-rich phases, respectively.

According to the condition of spontaneous dissolution $(\Delta G<$ 0 ) and the condition of thermodynamic equilibrium (eqn (2)), solubility can be estimated by eqn (3).

$$
\frac{\mathrm{d} \Delta G_{\mathrm{m}}}{\mathrm{d} c}=\Delta G_{\mathrm{m}}^{\prime}=0
$$

In order to estimate solubility we need a model which defines the terms of eqn (1); we used the Flory-Huggins lattice model $^{28}$ for this purpose in the present study. Although the model has limitations, it is relatively simple and can be used for comparative purposes. The lattice used is presented in Fig. 3 and shows that the sorbitol molecule is quite large compared to the repeating unit of PP considerably limiting the entropy change of mixing. The arrangement of the sorbitol molecule in the lattice was estimated by using the model calculations of Smith et $a .^{29}$ According to the Flory-Huggins model the enthalpy and entropy terms of the free energy of mixing can be expressed as

$$
\Delta S_{\mathrm{m}}=-R\left(\varphi_{1} \ln \varphi_{1}+\frac{\varphi_{2}}{N_{\mathrm{p}}} \ln \varphi_{2}\right)
$$

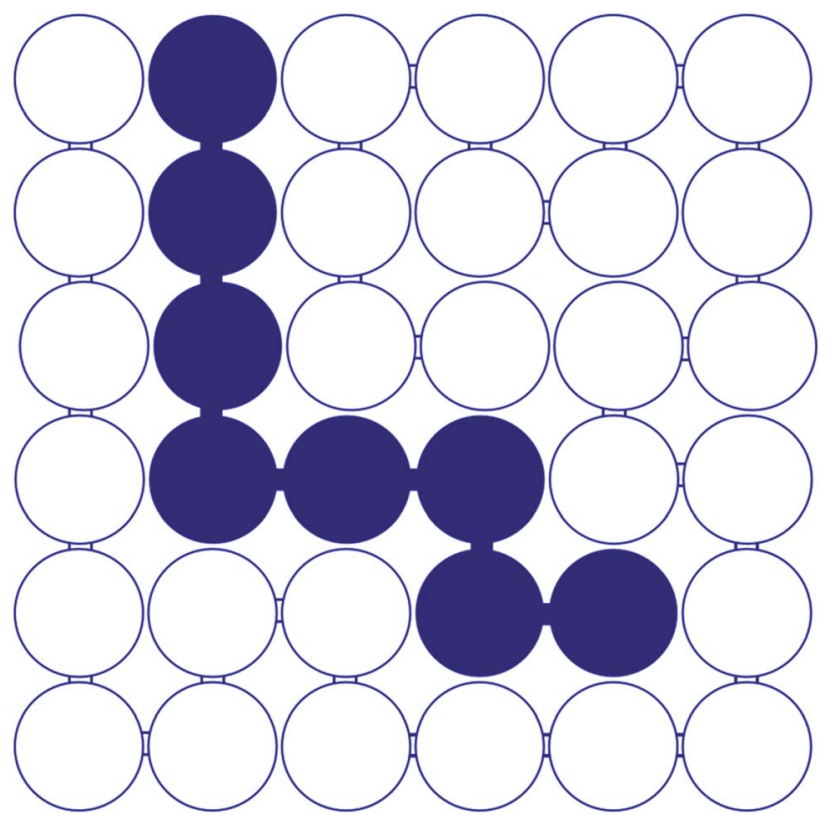

Fig. 3 Lattice model for the estimation of the solubility of sorbitols in PP; full circles: sorbitol; empty circles: PP. and

$$
\Delta H_{\mathrm{m}}=R T \chi \varphi_{1} \varphi_{2}+\Delta H_{\mathrm{melt}} \varphi_{1}
$$

where $\varphi_{1}$ is the volume fraction of the sorbitol, $\varphi_{2}$ is that of the polymer, $R$ is the universal gas constant, $N_{\mathrm{p}}$ is the degree of polymerization of PP, $T$ is absolute temperature, $\chi$ is the FloryHuggins interaction parameter and $\Delta H_{\text {melt }}$ is the heat of fusion of the sorbitol. Eqn (5) shows that the crystalline nature of the additive further limits solubility. The only unknown in the equations is the Flory-Huggins interaction parameter, which was calculated from the Hildebrand solubility parameters of the components. ${ }^{30}$

$$
\chi=\frac{V_{\mathrm{s}}\left(\delta_{\mathrm{s}}-\delta_{\mathrm{PP}}\right)^{2}}{R T}
$$

where $V_{\mathrm{s}}$ is a reference segment volume, while $\delta_{\mathrm{s}}$ and $\delta_{\mathrm{PP}}$ are the solubility parameters of the sorbitol and PP, respectively. The estimated van der Waals volume of PP repeating units was chosen as reference volume, which was calculated from group contributions; $;^{31,32}$ the $V_{\mathrm{s}}$ value of $31 \mathrm{~cm}^{3} \mathrm{~mol}^{-1}$ corresponding to $51 \AA^{3}$ per repeating unit was used in the calculations as a result. Accordingly, a sorbitol molecule occupies approximately 10 cells in the lattice, which agrees well with the prediction of Smith et al. ${ }^{29}$ showing that sorbitol molecules are one order of magnitude larger (400-600 $\AA^{3}$ per sorbitol molecule) than a PP repeating unit (see Fig. 3). Recently a slightly modified formula was proposed by Miller-Chou and Koenig, ${ }^{33}$ but its use practically did not modify the results of our calculations. Solubility parameters were calculated from the group contributions of Van Krevelen and Hoftzyer. ${ }^{31}$ This latter approach means a further limitation and simplification, but suffices for comparative purposes, for the estimation of the influence of the chemical structure of the sorbitol on solubility and nucleating efficiency.

The dependence of the free energy of mixing $\left(\Delta G_{\mathrm{m}}\right)$ and that of its first derivative $\left(\Delta G_{\mathrm{m}}^{\prime}\right)$ on sorbitol content is presented in Fig. 4 at $127{ }^{\circ} \mathrm{C}$ for MDBS (Millad 3940). We can see that the predicted solubility is very small at this temperature, namely below $4000 \mathrm{ppm}$. It is interesting to note that this value is much smaller than the ones determined by Smith et al. ( 2.5 and $5 \mathrm{wt} \%$ for Millad 3988 and NX 8000, respectively) using optical microscopy but agrees well with everyday practice at least in its magnitude. The temperature dependence of predicted solubility $\left(c_{\mathrm{c}}\right)$ determined in the way indicated in Fig. 4 is presented in Fig. 5 for the same clarifier. Solubility was calculated both for the amorphous and the crystalline additive, and the difference is striking. The solubility of the crystalline additive is at least one order of magnitude smaller than that of the amorphous compound. This difference explains well the necessity of processing sorbitol containing compounds at relatively high temperatures in order to achieve any kind of efficiency in nucleation and clarification. ${ }^{34,35}$ Accordingly, the second term in eqn (5) cannot be neglected and crystallinity must be always considered in the estimation of the solubility of sorbitols.

Solubility values determined experimentally in the way shown in Fig. 2 and estimated by the approach presented above 


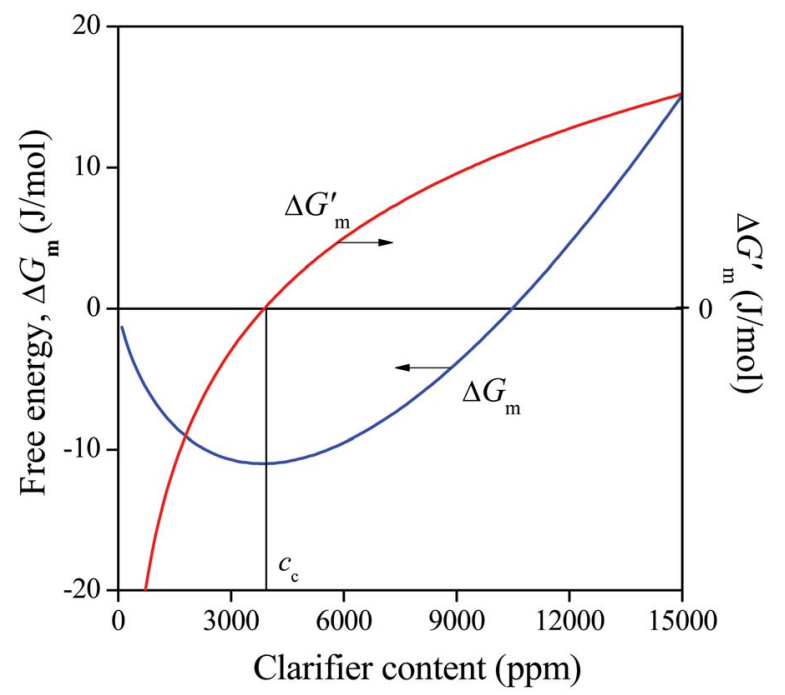

Fig. 4 Calculated free energy of mixing and its derivative plotted as a function of clarifier content in the concentration range of interest; MDBS (Millad 3940), $127^{\circ} \mathrm{C}$; determination of estimated solubility $\left(c_{\mathrm{c}}\right)$.

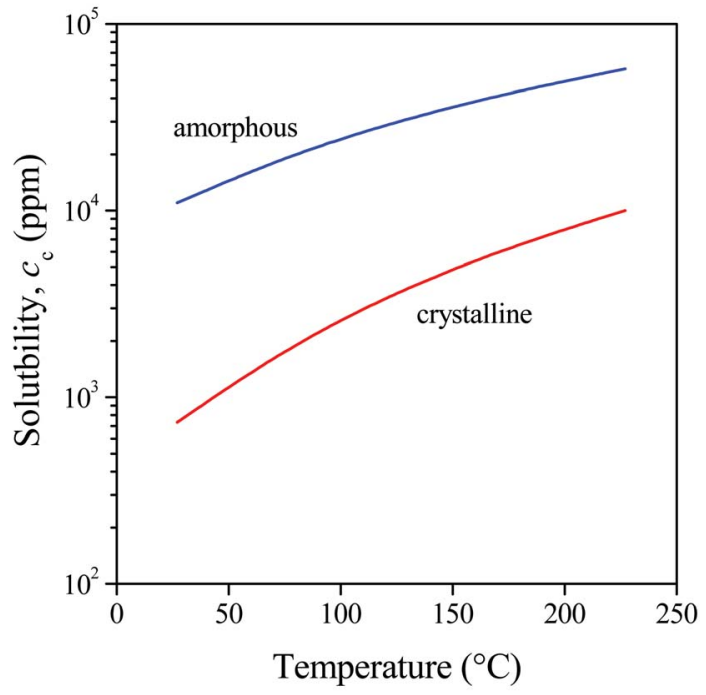

Fig. 5 Effect of sorbitol crystallinity and temperature on the solubility of the clarifier MDBS in PP.

(see Fig. 4) are plotted against each other in Fig. 6. A tendency can be seen, but the correlation is rather loose with a considerable deviation of MDBS (Millad 3940) from the general tendency. A possible reason for the deviation is the strong effect of kinetics as pointed out also by Kristiansen et al. ${ }^{16}$ in their first paper. The time dependence of phase separation, nucleation and crystallization must influence the value of $c_{\mathrm{e}}$ considerably. Nevertheless, the model calculations presented above prove that sorbitols are soluble in PP, but only in very small amounts. Thus, any factor influencing dissolution, like crystalline structure and processing temperature, will affect also the efficiency of the clarifier.

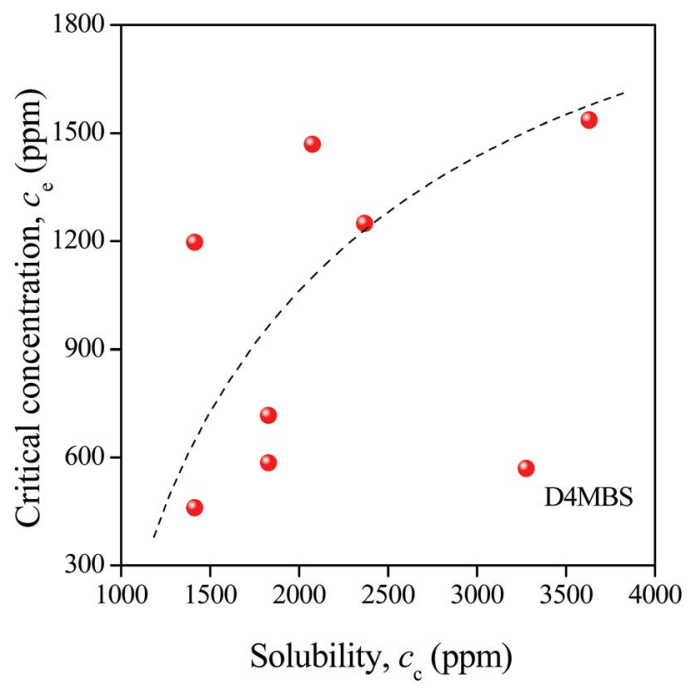

Fig. 6 Loose correlation between experimental $\left(c_{\mathrm{e}}\right)$ and predicted $\left(c_{\mathrm{c}}\right)$ solubility of the clarifiers listed in Table 1 in PP at the temperature of solidification. The broken line is to guide the eye and indicates the trend of the correlation.

\subsection{Sorbitol structure, characteristic temperatures}

As the analysis of the product after synthesis shows, sorbitols are mainly crystalline materials. However, they are obtained in the form of a fine powder, which is rather difficult to disperse in the polymer, a common problem of sorbitol clarifiers. The OM micrographs of a clarifier (MDBS, Millad 3940) are presented in Fig. 7 before (7a) and after (7b) thermally induced transformation. For this transformation the sample was first heated fast $\left(50{ }^{\circ} \mathrm{C} \mathrm{min}^{-1}\right)$ to a temperature somewhat below the expected transformation temperature identified by preliminary experiments and then slowly $\left(2{ }^{\circ} \mathrm{C} \mathrm{min}^{-1}\right)$ further to determine this characteristic value as precisely as possible. The micrograph shows clearly that the original fine powder (Fig. 7a) transforms during heating and forms very fine needle like crystals (Fig. 7b). All sorbitols except D4NBS underwent such a transformation. According to our knowledge this transformation has never been shown in the literature before and its possible impact on nucleation has consequently not been considered either.

Two questions may be raised in relation with the transformation: the process behind, and its effect on nucleation efficiency. The original and the transformed powders were studied by XRD. A representative example is shown in Fig. 8. The transformed powder was annealed under the same conditions as the samples in the OM experiments. The two patterns are very similar to each other. Both powders are crystalline, and the crystal modification does not change upon heat treatment. As a consequence we may conclude that transformation results in crystal perfection, an increase in crystallinity, in crystals with different shape and larger perfection. Increased crystallinity might hinder solubility, but the larger surface area of the needle like crystals should improve and accelerate it considerably. One might speculate that not solubility, but transformation and the needle like crystals initiate nucleation and result in 


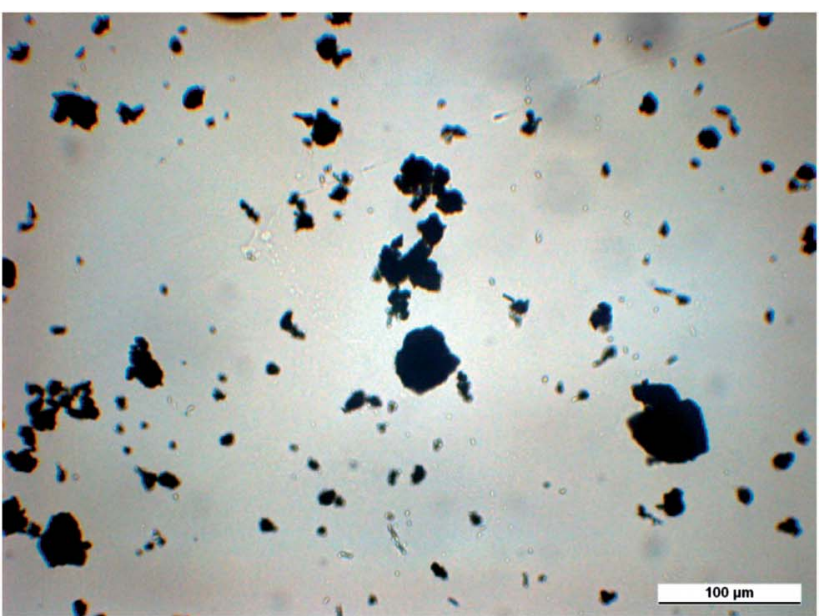

a)

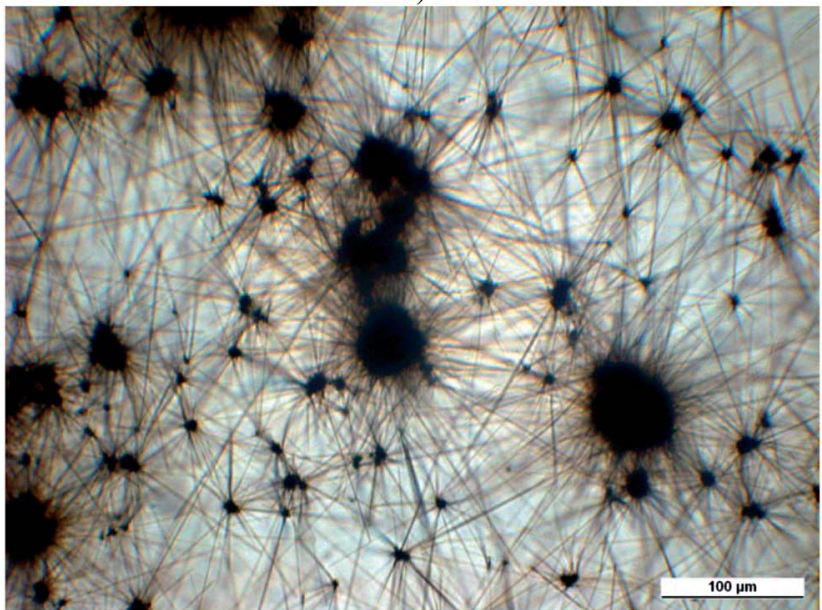

b)

Fig. 7 Transformation of the crystalline structure of MDBS (Millad 3940) powder upon heating. Micrographs were recorded at $30{ }^{\circ} \mathrm{C}$ (a) and $210^{\circ} \mathrm{C}(\mathrm{b})$, respectively.

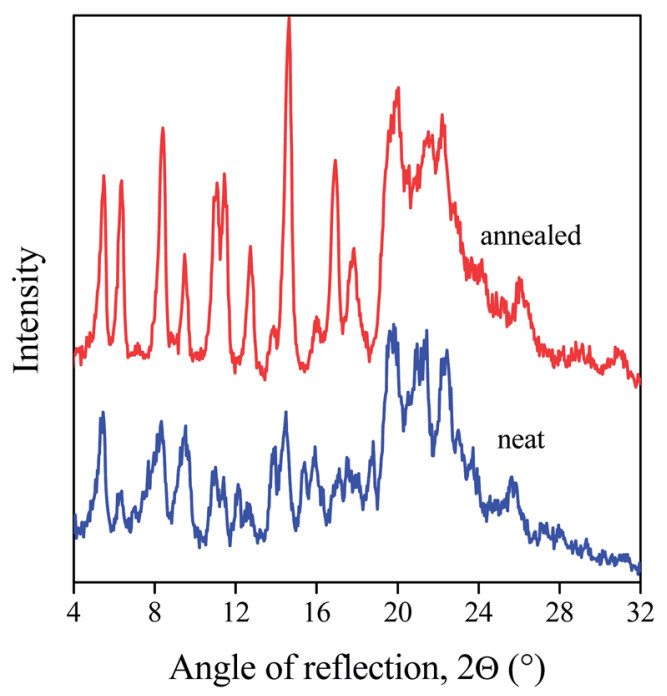

Fig. 8 Effect of heat treatment on the crystalline structure of DBS; crystal perfection. clarification, but the size of the crystals is in the micron range, thus they should scatter light and deteriorate optical properties. Therefore solubility must be important and play a role in the effect of sorbitol clarifiers. Further increase of temperature results in the melting of the crystals, while subsequent cooling in the formation of fibrils and a network structure as shown earlier. ${ }^{\mathbf{1 1 , 1 9}}$ The fibrils formed in this way are also large, micronsized, and cannot be related to nucleation and clarification. The small amounts soluble in PP must form the nanometer sized fibrils predicted and shown earlier, ${ }^{24,25}$ which are not visible even in the light microscope.

The transformation temperature was determined for all sorbitols included in this study and the values are presented in Table 2 together with melting temperatures determined by DSC. The predicted solubility is also listed in Table 2 for comparison. According to this table, transformation temperatures are always significantly lower than melting temperatures indicating that transformation must play a role in dissolution and nucleation. This assumption is strongly supported by the fact and explains that often processing temperatures much lower than the melting point of the sorbitol are sufficient to achieve good clarity. A good example is the DMDBS (Millad 3988) clarifier and the work of Kristiansen et al. ${ }^{\mathbf{1 6}}$ The highest temperature used for processing by the authors was $260{ }^{\circ} \mathrm{C}$ and different processing temperatures between 230 and $260{ }^{\circ} \mathrm{C}$ were used for the preparation of samples for their various measurements, which did not seem to influence results and conclusions. We must emphasize here that the melting temperature of the product is $273.7{ }^{\circ} \mathrm{C}$ determined by DSC. On the other hand, its transformation or recrystallization temperature is $226.0^{\circ} \mathrm{C}$, which is below all temperatures used, thus transformation must play a role in dissolution and nucleation.

\subsection{Effect and efficiency}

The effect of the chemical structure on the efficiency of the clarifiers studied is shown in Fig. 9 where haze is plotted as a function of clarifier content for the sorbitols listed in Table 1. The stepwise decrease in haze with increasing clarifier content indicates the solubility of the additive in the polymer and is in complete agreement with the effect shown already in Fig. 1 for

Table 2 Predicted solubility and critical temperatures of the sorbitol clarifiers used in the study

\begin{tabular}{llll}
\hline Clarifier & $c_{\mathrm{c}}(\mathrm{ppm})$ & $T_{\mathrm{t}}{ }^{a}\left({ }^{\circ} \mathrm{C}\right)$ & $T_{\mathrm{m}}{ }^{b}\left({ }^{\circ} \mathrm{C}\right)$ \\
\hline D4MoBS & 1410 & 177.0 & 192.2 \\
D3MoBS & 1830 & 169.0 & 202.2 \\
D4NBS & - & - & 269.6 \\
D4ClBS & 3630 & 208.0 & 236.5 \\
DBS & 2080 & 157.5 & 216.3 \\
DBS & 1410 & 150.0 & 227.1 \\
MDBS & 3280 & 147.5 & 225.8 \\
DMDBS & 2370 & 226.0 & 273.7 \\
DOPMN & 1830 & 176.0 & 245.7
\end{tabular}

${ }^{a}$ Transformation temperature. ${ }^{b}$ Melting temperature determined by DSC. 


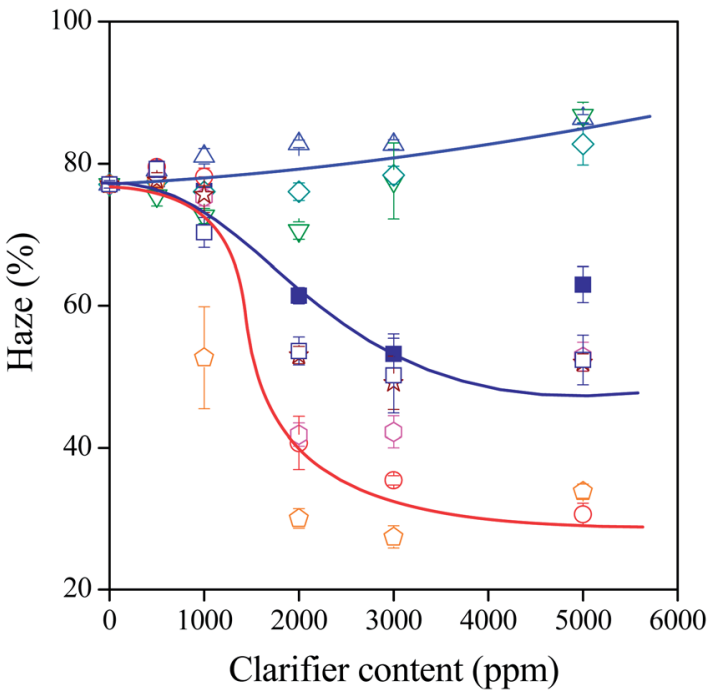

Fig. 9 Haze plotted against clarifier content. Effect of chemical structure on the efficiency of sorbitols as clarifiers. Symbols: $\triangle$ D4NBS; $\checkmark$ D3MoBS; $\diamond$ D4MoBS; $\square \mathrm{DBS} ; \square \mathrm{DBS}(\mathrm{M} 3905) ;$ MDBS; $\triangle \mathrm{DMDBS} ; 0$ D4CIBS; $\triangle \mathrm{DOPMN}$.

the peak temperature of crystallinity. The height of the step depends on the efficiency of the clarifier, i.e. on its solubility in the polymer. ${ }^{6,20}$ Large differences are seen in effect depending on the chemical structure of the clarifier. Only three correlations are drawn to guide the eye, but both the tendency and the differences are clear. Most of the haze values determined at $5000 \mathrm{ppm}$ are above the smallest value measured, because of limited solubility resulting in larger sorbitol crystals scattering light.

The results presented in the previous section and in Table 2 indicate the importance of characteristic temperatures. In order to check the influence of processing on clarifying efficiency, the composition dependence of haze was determined at various temperatures. Some results are presented in Fig. 10 for DMDBS, the Millad 3988 clarifier. PP containing the nucleating agent was processed at $190,200,210,220$ and $240^{\circ} \mathrm{C}$. Only three series are plotted in Fig. 10 to facilitate viewing. A large jump in haze is observed above $190{ }^{\circ} \mathrm{C}$ and a practically constant effect above $220{ }^{\circ} \mathrm{C}$. We must emphasize here the fact that the transformation temperature of the sorbitol is $226^{\circ} \mathrm{C}$ and its melting point is $273.7^{\circ} \mathrm{C}$. The same applies to other sorbitols as well. PP containing DBS, for example, was processed between 170 and $230{ }^{\circ} \mathrm{C}$, and no difference in effect was seen in this range (not shown), because the transformation temperature of this compound is $157.5{ }^{\circ} \mathrm{C}$, while its melting point is $216.3{ }^{\circ} \mathrm{C}$. Obviously, rather crystal transformation temperature and not melting determines the effect and efficiency of sorbitol clarifiers.

Finally, in order to see the influence of chemical structure and solubility on the efficiency of the sorbitols, the smallest haze achieved with each clarifier was plotted against the Flory-Huggins interaction parameter in Fig. 11. Apart from the effect of D4ClBS, the correlation is clear, efficiency increases with decreasing interaction parameter, i.e.

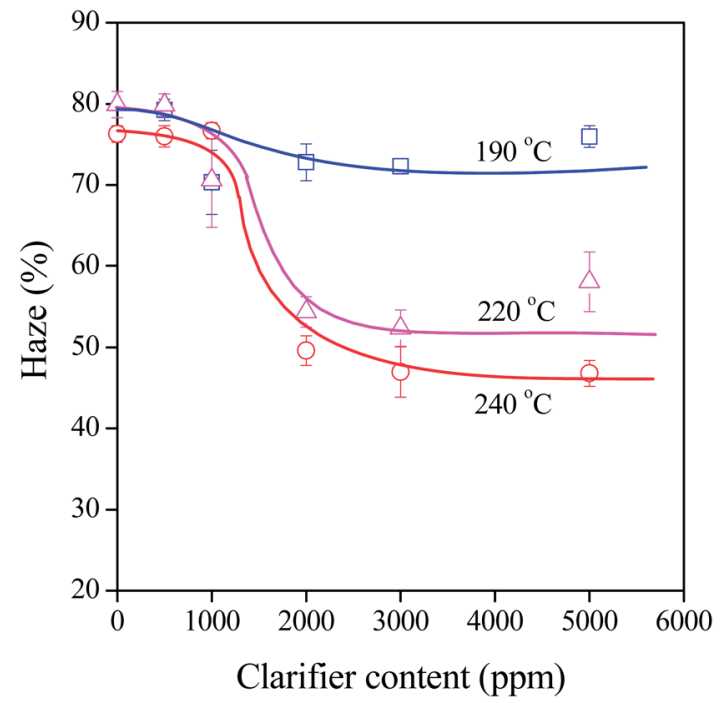

Fig. 10 Effect of processing temperature on the efficiency of DMDBS sorbitol as clarifier.

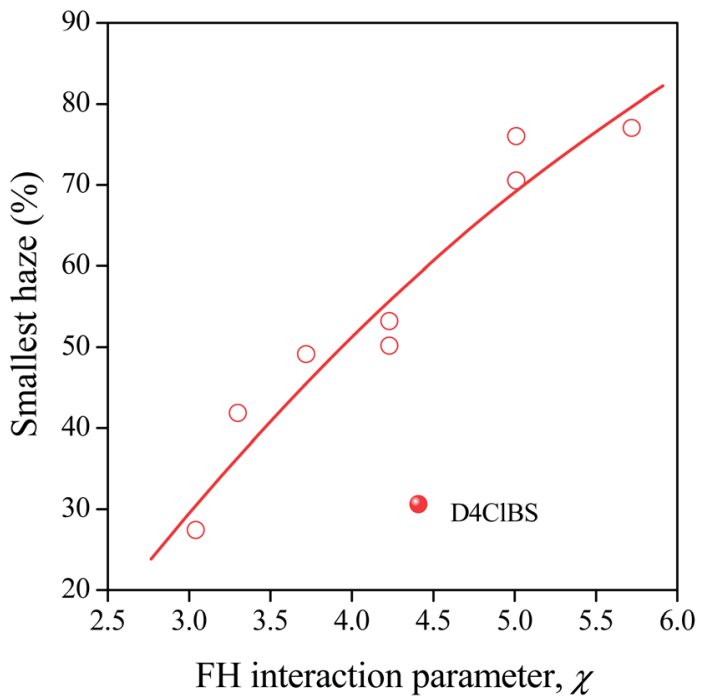

Fig. 11 Correlation between the Flory-Huggins interaction parameter of and the smallest haze achieved by the various clarifiers studied.

increasing solubility. Naturally, the correlation must be treated with care, since several other factors, like synthesis conditions, transformation and kinetic effects all influence solubility, nucleation and clarification. The dissimilar behavior of D4ClBS needs further study and considerations. The correlation, however, agrees well with the results presented above and can be explained reasonably. As shown in Fig. 5 and as expected, solubility increases with temperature, thus larger solubility at the temperature of solidification means larger dissolved amounts at higher temperatures as well. As a consequence, more clarifier will precipitate and crystallize upon cooling resulting in larger number of fibrils, larger nucleus density and efficiency. A close correlation was shown between nucleus density and clarity before. ${ }^{16,20}$ 
Naturally this tentative explanation cannot take into account the size of the fibrils formed during the crystallization of the clarifier or the structure and role of the sorbitol network formed. These might cause the dissimilar effect of D4ClBS and as mentioned, the phenomenon needs further study and explanation.

In order to check the assumption presented above, nucleus density was calculated from the non-isothermal DSC traces used for the estimation of $c_{\mathrm{e}}$ by an approach developed recently. ${ }^{36}$ Changes in the volume of crystalline material are calculated as a function of temperature from crystallization traces using the density of the crystalline phase $\left(0.936 \mathrm{~g} \mathrm{~cm}^{-3}\right){ }^{2}$ Accordingly, the time dependence of nucleus density can be given as

$$
\begin{gathered}
N_{t}=\frac{3 \Delta V_{\mathrm{cr}}}{4 \pi\left(G_{\tau} t_{i}\right)^{3}}-N_{t-t_{i}}{ }^{2-A_{x}} \\
A_{x}=\left(\frac{1}{1-x_{t}}\right)^{\left(1-x_{t}\right) d}
\end{gathered}
$$

where $V_{\text {cr }}$ is the volume of crystalline material, $N$ is nucleus density, $G$ is crystal growth rate and $t$ is time. $A_{x}$ is an internal empirical function, which takes into account the closing of free growing surfaces during crystallization and $x_{t}$ is the conversion. Constant $d$ depends on the dimensionality of growth and its value is three in our case (spherulitic growth). Final nucleus density is obtained as the sum of $N_{t}$ from the start to the end of the crystallization process. The smallest haze achieved is plotted against nucleus density in Fig. 12. As shown by the figure, the correlation is very close for all clarifiers except D3MoBS. The deviation might have the same reason as for that of D4ClBS in the previous figure, but it needs further study. Nevertheless, we can conclude with rather large certainty that larger solubility results in larger nucleus density and better (i.e. lower) haze.

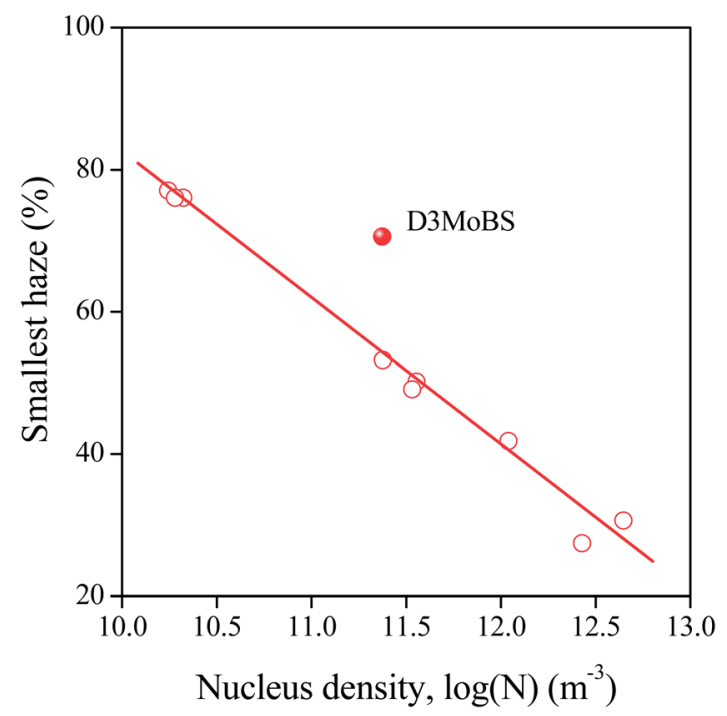

Fig. 12 Close relationship between nucleus density and the smallest haze achieved in clarified PP.

\section{Conclusions}

Model calculations carried out for the estimation of the solubility of a considerable number of sorbitol clarifiers showed that solubility in PP is small, a few 1000 ppm at most, in agreement with industrial experience. Solubility is determined by the chemical structure of the sorbitol and the heat of fusion of the latter changes solubility by at least one order of magnitude. Solubility can be estimated reasonably by the Flory-Huggins lattice theory. The morphology of most sorbitols transforms at a temperature much below their melting point upon heating. The transformation, which is accompanied by crystal perfection, seems to influence melting and solubility which indicates that polypropylenes containing a sorbitol clarifier must not necessarily be heated above the melting temperature of the nucleating agent in order to achieve the desired effect, the decrease of haze. A fibrillar structure forms upon cooling of molten sorbitols, but the diameter of the fibrils is much larger than those forming in the polymer melt. The nucleation effect of the clarifier depends on its solubility, but also on processing conditions, mostly on the temperature of the polypropylene melt. Solubility decreases with increasing polarity, substituents containing heteroatoms (alkoxy, halogen, nitro) seem to be less advantageous than those consisting of only alkyl groups. Nucleus density is related to the amount of dissolved clarifier. A rather good correlation was found between the Flory-Huggins interaction parameter of sorbitols and the minimum haze achieved, which was explained with the effect of solubility and nucleus density.

\section{Acknowledgements}

The help and advice of Béla Turcsányi and Gábor Pál Pénzes in the synthesis of the sorbitols and that of István Sajó in the XRD measurements are highly appreciated. We acknowledge the assistance of Attila Domján in the NMR characterization of the sorbitols synthesized. The authors also acknowledge the financial support of the National Scientific Research Fund of Hungary (OTKA Grant no. K 101124 and PD 109346) for the project on structure-property correlations of polymeric materials. Another author (Alfréd Menyhárd) would like to express his gratitude to the János Bolyai Research Scholarship of the Hungarian Academy of Sciences for its financial support.

\section{References}

1 M. Gahleitner, M. Kirchberger, K. Bernreitner, B. R. Kona and L. Blayac, Kunststoffe Int., 2010, 100, 25-27.

2 F. M. Willmouth, in Optical Properties of Polymers, ed. G. H. Meeten, Elsevier, London, 1986, pp. 265-333.

3 J. H. Bheda and J. E. Spruiell, Polym. Eng. Sci., 1986, 26, 736745.

4 S. A. White and S. K. Doun, Polym. Eng. Sci., 1992, 32, 14261432.

5 D. Del Duca, D. Malucelli, G. Pellegatti and D. Romanini, in Polypropylene Handbook, ed. N. Pasquini, Hanser Verlag, Munich, 2005, pp. 307-357. 
6 M. Gahleitner, C. Grein, S. Kheirandish and J. Wolfschwenger, Int. Polym. Process., 2011, 26, 2-20.

7 A. Thierry, B. Fillon, C. Straupé, B. Lotz and J. Wittmann, Prog. Colloid Polym. Sci., 1992, 87, 28-31.

8 C. Marco, G. Ellis, M. A. Gomez and J. M. Arribas, J. Appl. Polym. Sci., 2002, 84, 2440-2450.

9 M. Kristiansen, T. Tervoort and P. Smith, Polymer, 2003, 44, 5885-5891.

10 M. Tenma, N. Mieda, S. Takamatsu and M. Yamaguchi, J. Polym. Sci., Part B: Polym. Phys., 2008, 46, 41-48.

11 T. L. Smith, D. Masilamani, L. K. Bui, R. Brambilla, Y. P. Khanna and K. A. Gabriel, J. Appl. Polym. Sci., 1994, 52, 591-596.

12 T. Liu, H. Meng, X. Y. Sheng and X. Zhang, Polym.-Plast. Technol. Eng., 2011, 50, 1165-1169.

13 Y. F. Zhang, X. Li and X. S. Wei, J. Therm. Anal. Calorim., 2010, 100, 661-665.

14 M. Blomenhofer, S. Ganzleben, D. Hanft, H.-W. Schmidt, M. Kristiansen, P. Smith, K. Stoll, D. Mader and K. Hoffmann, Macromolecules, 2005, 38, 3688-3695.

15 F. Abraham, S. Ganzleben, D. Hanft, P. Smith and H. W. Schmidt, Macromol. Chem. Phys., 2010, 211, 171-181.

16 M. Kristiansen, M. Werner, T. Tervoort, P. Smith, M. Blomenhofer and H. W. Schmidt, Macromolecules, 2003, 36, 5150-5156.

17 K. Bernland, T. Tervoort and P. Smith, Polymer, 2009, 50, 2460-2464.

18 E. Nedkov and T. Dobreva, e-Polymers, 2002, 042.

19 K. Resch, G. M. Wallner, C. Teichert and M. Gahleitner, Polym. Eng. Sci., 2007, 47, 1021-1032.

20 A. Menyhárd, M. Gahleitner, J. Varga, K. Bernreitner, P. Jääskeläinen, H. Řysćd and B. Pukánszky, Eur. Polym. J., 2009, 45, 3138-3148.
21 D. S. Langhe, J. K. Keum, A. Hiltner and E. Baer, J. Polym. Sci., Part B: Polym. Phys., 2011, 49, 159-171.

22 Y. Jin, A. Hiltner and E. Baer, J. Polym. Sci., Part B: Polym. Phys., 2007, 45, 1788-1797.

23 D. S. Langhe, A. Hiltner and E. Baer, J. Appl. Polym. Sci., 2012, 125, 2110-2120.

24 A. Thierry, C. Straupe, J. C. Wittmann and B. Lotz, Macromol. Symp., 2006, 241, 103-110.

25 J. Lipp, M. Shuster, A. E. Terry and Y. Cohen, Langmuir, 2006, 22, 6398-6402.

26 E. Földes and B. Turcsányi, J. Appl. Polym. Sci., 1992, 46, 507515.

27 E. Földes, J. Appl. Polym. Sci., 1993, 48, 1905-1913.

28 P. J. Flory, J. Chem. Phys., 1942, 10, 51-61.

29 T. L. Smith, D. Masilamani, L. K. Bui, Y. P. Khanna, R. G. Bray, W. B. Hammond, S. Curran, J. J. Belles and S. Bindercastelli, Macromolecules, 1994, 27, 31473155.

30 The Solubility of Non-Electrolytes, ed. J. H. Hildebrand and R. L. Scott, Reinhold, New York, 1959.

31 Properties of polymers: their correlation with chemical structure; their numerical estimation and prediction from additive group contributions, ed. D. W. Van Krevelen and P. J. Hoftzyer, Elsevier, Amsterdam, 3rd edn, 1990.

32 A. Bondi, J. Phys. Chem., 1964, 68, 441-451.

33 B. A. Miller-Chou and J. L. Koenig, Prog. Polym. Sci., 2003, 28, 1223-1270.

34 L. Balzano, G. Portale, G. W. M. Peters and S. Rastogi, Macromolecules, 2008, 41, 5350-5355.

35 J. W. Housmans, M. Gahleitner, G. W. M. Peters and H. E. H. Meijer, Polymer, 2009, 50, 2304-2319.

36 A. Menyhárd, J. Varga, M. Bredács, Zs. Horváth and G. Simon, J. Therm. Anal. Calorim., submitted. 